\title{
ARTICLE OPEN \\ Exploring the role of quantitative feedback in inhaler technique education: a cluster-randomised, two-arm, parallel-group, repeated-measures study
}

\author{
Mariam Toumas-Shehata ${ }^{1}$, David Price ${ }^{2}$, Iman Amin Basheti ${ }^{3}$ and Sinthia Bosnic-Anticevich ${ }^{1,4}$
}

BACKGROUND: Feedback is a critical component of any educational intervention. When it comes to feedback associated with inhaler technique education, there is a lack of knowledge on its role or its potential to solve the major issue of poor inhaler technique.

AIMS: This study aims to explore the role of feedback in inhaler technique education and its impact on the inhaler technique of patients over time.

METHODS: A parallel-group, repeated-measures study was conducted in the community pharmacy in which the effectiveness of current best practice inhaler technique education utilising qualitative visual feedback (Group 1) was compared with a combination of qualitative and quantitative visual feedback (Group 2). The impact of these two interventions on inhaler technique maintenance was evaluated. Community pharmacists were randomly allocated to recruit people with asthma who were using a dry powder inhaler. At Visit 1 their inhaler technique was evaluated and education delivered and they were followed up at Visit 2 (1 month later).

RESULTS: Both educational interventions resulted in an increase in the proportion of patients with correct inhaler technique: from $4 \%$ to $51 \%$ in Group 1 and from 6\% to 83\% in Group 2 (Pearson's Chi-Squared, $P=0.03, n=49$, and Pearson's Chi-Squared, $P=0.01$, $n=48$, respectively). The magnitude of improvement was statistically significantly higher for Group 2 compared with Group 1 ( $n=97, P=0.02$, Pearson's Chi-Square test).

CONCLUSIONS: The nature of feedback has an impact on the effectiveness of inhaler technique education with regard to correct inhaler technique maintenance over time.

npj Primary Care Respiratory Medicine (2014) 24, 14071; doi:10.1038/npjpcrm.2014.71; published online 13 November 2014

\section{INTRODUCTION}

The most commonly used method of drug delivery in asthma is inhalation. The advantages of inhaled therapy have been established; it facilitates improved drug delivery to the site of action in minimal doses. ${ }^{1}$ However, a high incidence of incorrect use remains a challenge, with $50-90 \%$ of patients using their inhalers incorrectly. ${ }^{2-10}$ This is of critical importance as the inhaler technique has been shown to be associated with asthma control, lung function, perceived control of asthma and quality of life. , $^{8,112}$

Fortunately, with appropriate training, patients are able to achieve the correct inhaler technique. However, maintaining the correct inhaler technique over time remains problematic., ${ }^{7,8}$ Approximately $50 \%$ of patients have subsequent difficulty in maintaining the correct inhaler technique, irrespective of the inhaler device used or the duration of follow-up (ranging from 2 to 6 weeks after education). $7,10,13-15$

Although there is substantial data on the failure of patients to maintain the correct technique, there is little research on the actual factors that have an impact on inhaler technique maintenance. Recent research has found that maintaining the correct inhaler technique is a complex process and is related to asthma control, inhaler device and motivation. ${ }^{16}$ Understanding the way these factors influence correct inhaler technique maintenance is important, and identifying ways in which health-care professionals (HCPs) in practice can deliver more effective inhaler technique education needs to be identified. Understanding the nature and content of the education delivered by HCPs may be the key.

Delivery of inhaler technique education involves two main processes: evaluation of the inhaler technique; and provision of feedback on erroneous steps. Specifically, this involves HCPs observing how the patient uses their inhaler and comparing this technique with an inhaler technique checklist. Depending on the ability of the patient to use the inhaler correctly, the HCP provides specific feedback on how to rectify the errors. It has been found that the nature of this feedback has significant impact on its effectiveness. ${ }^{7,10}$ This suggests that, when reviewing the inhaler technique education delivered to patients, it is important to review the concept of 'feedback'. $7,8,13,17,18$

Feedback can be given qualitatively or quantitatively. Research shows that, when it comes to the optimal delivery of feedback, quantitative feedback should be used. ${ }^{19}$ Currently, the nature of feedback in evidence-based inhaler technique educational interventions is qualitative. The aim of this research is to compare the effectiveness of the current best practice, qualitative visual feedback, with a combination of qualitative and quantitative visual feedback on inhaler technique maintenance over time.

${ }^{1}$ Woolcock Institute of Medical Research and The University of Sydney, Glebe, NSW, Australia; ${ }^{2}$ Department of Primary Care Respiratory Medicine, University of Aberdeen, Aberdeen, Scotland; ${ }^{3}$ Clinical Pharmacy, Applied Science University, Amman, Jordan and ${ }^{4}$ Sydney Local Health District, NSW, Australia.

Correspondence: M Toumas-Shehata (mtou5568@uni.sydney.edu.au)

Received 18 December 2013; revised 11 June 2014; accepted 20 July 2014 


\section{MATERIALS AND METHODS}

\section{Overall study design}

This study took the form of a cluster-randomised two-arm parallel group, repeated-measures design in which people with asthma received education regarding their inhaler technique in the form of either qualitative visual feedback (verbal feedback with a physical demonstration) (Group 1) or a combination of qualitative and quantitative visual feedback (verbal feedback with physical demonstration plus objective (graphical) feedback) (Group 2). Inhaler technique education was provided by trained community pharmacists who followed up participants after 1 month.

The study was approved by the University of Sydney Ethics Committee. Written informed consent was obtained prior to participation.

\section{Pharmacist training}

A convenient sample of 19 community pharmacists were recruited and randomised to deliver qualitative visual feedback (Group 1) or a combination of qualitative and quantitative visual feedback (Group 2).

Training of community pharmacists occurred on an individual basis with the researcher (MTS) delivering a 2-h one-on-one training session to each pharmacist in their own community pharmacy.

Group 1 pharmacists were trained as per a train-the-trainer approach and an established pharmacist-training program. ${ }^{15}$ A DVD showing HCPs delivering inhaler technique education to people with asthma was used to consolidate the training of pharmacists. Pharmacists also received an update on basic asthma management and inhaled medications.

Group 2 pharmacists were also trained as per a train-the-trainer approach and an established pharmacist-training programme ${ }^{15}$ with an additional quantitative feedback process.

The quantitative feedback involved the use of a portable hand-held spirometer (Inhalation Manager (IM, TEVA Pharmaceutical Industries Ltd, Tel Aviv, (srael)), which has been developed with the ability to assess breathing manoeuvres associated with the use of different inhaler devices (Figure 1). The IM is a preprogrammed device that can measure breathing manoeuvres and provides feedback both in numeric and visual/graphic forms. Actual breathing manoeuvres are then compared with optimal manoeuvres for a particular inhaler. This allows the patient to see exactly where they are making errors and to what extent (Figure 2). A DVD showing HCPs delivering inhaler technique education to people with asthma was used to consolidate the training of pharmacists (The DVD was funded through Australian Research Council Linkage Project LP LP0882737). ${ }^{20}$ Pharmacists also received an update on basic asthma management and inhaled medications.

\section{Participant recruitment}

The trained pharmacists identified potential participants as they entered the pharmacy and requested asthma medication or asthma-related advice. Inclusion criteria for participants were as follows: having a diagnosis of asthma and aged $\geqslant 18$ years; currently using a Turbuhaler $(\mathrm{TH})$ or Accuhaler (ACC) for the delivery of preventer asthma medication; and having been on the same asthma medication and dose regimen for a minimum of 1 month. Exclusion criteria for participants were as follows: medication not being self-administered; inability to speak or understand English; inability to return for the follow-up visit; and/or being involved in another clinical trial/study.

The purpose of the study was not withheld from the patient participants.

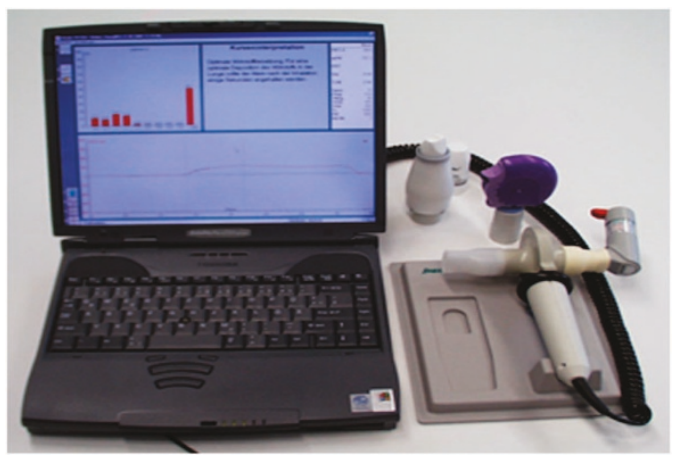

Figure 1. Photo of Inhalation Manager.

\section{Study visits}

Participants were required to visit their pharmacy at the commencement of the study (V1) and after 1 month for a follow-up (V2). At V1, participant data related to demographics, asthma history, asthma medications and previous inhaler technique instructions were collected. Asthma Control was also evaluated (Asthma Control Questionnaire ). ${ }^{21}$ The Asthma Control Questionnaire is a validated instrument evaluating asthma control based on symptoms and bronchodilator use. A lower score indicates better asthma control. A score $\geqslant 1.50$ means that a patients has an $88 \%$ chance of having asthma symptoms that are not well controlled. A change in the Asthma Control Questionnaire score of 0.5 is considered clinically meaningful. ${ }^{22}$

The participants' inhaler technique was assessed; they then received inhaler technique feedback based on whether they were randomised to Group 1 or Group 2. Group 1 participants received qualitative visual feedback (verbal feedback with a physical demonstration). Group 2 participants received additional quantitative visual feedback (verbal feedback with physical demonstration plus objective (graphical) feedback) (as described above).

The inhaler technique was reassessed, and Group 1 or Group 2 feedback was repeated until the participant was able to demonstrate the correct technique or after feedback had been provided a maximum of three times.

Participants returned to the pharmacy for a follow-up visit (V2) 4 weeks \pm 7 days after V1. At this visit, asthma control was evaluated (Asthma Control Questionnaire), ${ }^{21}$ and the inhaler technique was reassessed.

Inhaler technique assessment. The inhaler technique was assessed according to manufacturer-approved checklists (Table 1). These checklists were developed in collaboration with the National Prescribing Service, Sydney, Australia, through funding from the Australian Research Council Linkage Project LP LP0882737. Individuals were considered to have the correct technique if they were able to perform all steps in the checklist correctly.

\section{Data management}

Demographic data, asthma history, asthma medications and previous asthma technique instructions were analysed descriptively. Asthma control was compared within groups (at V1 and V2) as well as between Group 1 and Group 2. Inhaler technique data were represented in two ways: proportion of participants with correct technique and as the mean number of steps performed correctly for each device.

The proportion of patients with correct technique was determined by the number of participants with the correct technique (able to perform all steps correctly for the respective device) as a percentage of the total number of participants in that group.

Inhaler technique score was determined as the number of steps performed correctly out of the total number of steps for each inhaler. ${ }^{23}$ This was standardised between inhalers. For example, the total number of steps required to use an ACC was 10 (Table 1); if a participant completed only 4 steps correctly, their inhaler technique score was 4 . For the $\mathrm{TH}$, the number of steps required to use the inhaler correctly was 11 ; hence, the TH scores were transformed by a factor of $10 / 11$ for comparison. That is, the total number of steps performed correctly for the TH was divided by ' 11 ' and multiplied by ' 10 '.

Sample size calculation. Based on a study by Basheti et al. ${ }^{15}$ and an estimated difference of $30 \%$ in the proportion of participants with the correct inhaler technique at follow-up (Power $=0.8, P=0.05$ ), a sample size of 45 participants in each group was required.

On the basis of previous research conducted in a community pharmacy in Australia, involving a cluster design, asthma management and inhaler technique, consistently an intraclass correlation of 0.00 was determined, based on a cluster of 10 participants per pharmacy. This indicated that there is no cluster effect and therefore no need to include a cluster effect in the sample size calculation. ${ }^{8,24-26}$

\section{Statistical analysis}

Within-group comparisons. Mean inhaler technique scores, mean Asthma Control Scores for V1 and V2 (Wilcoxon's Signed Rank test) and the proportion of patients with correct technique for V1 and V2 (Pearson's Chi-Square test) were compared over time within groups.

Between-group comparisons. The mean inhaler technique score, the mean Asthma Control Scores (Mann-Whitney $U$ test) and the proportion of 


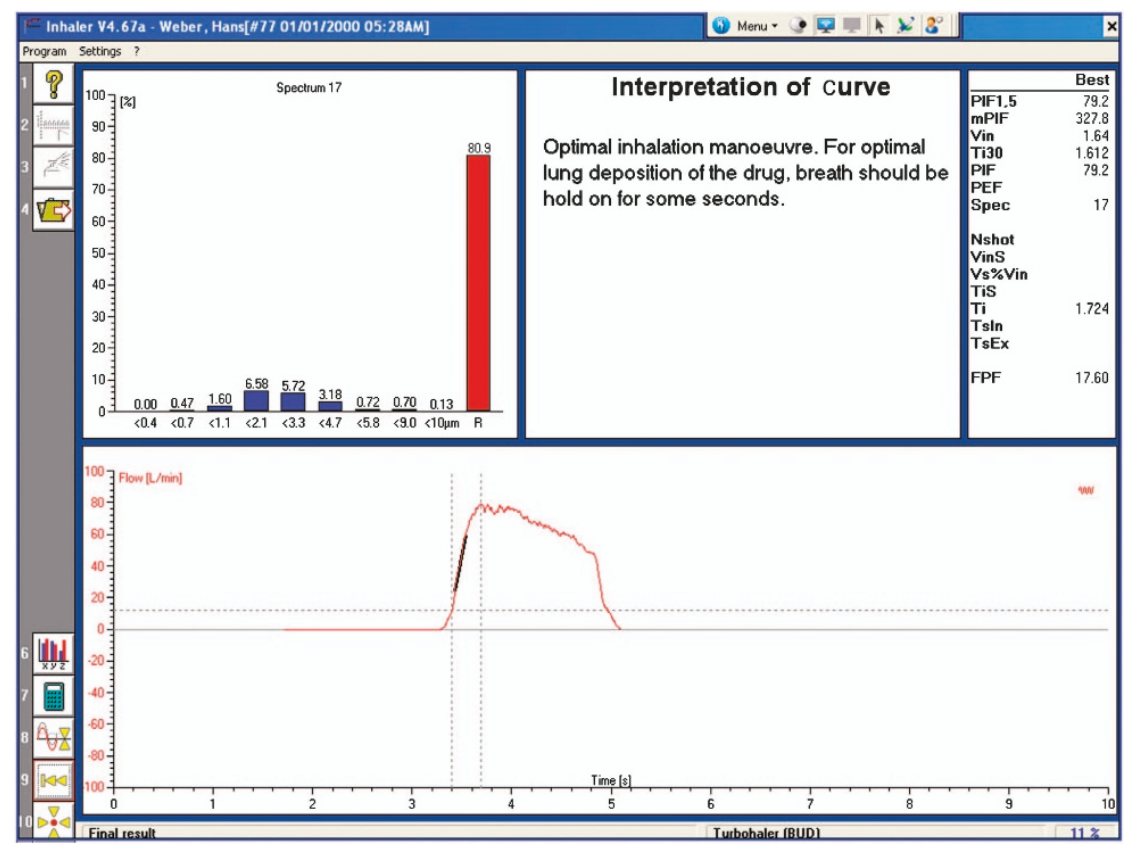

Figure 2. Example of output from Inhalation Manager.

Table 1. Itemised list of steps required to administer medication via an Accuhaler and Turbuhaler

\begin{tabular}{|c|c|c|}
\hline Step & Turbuhaler $(T H)$ & Accuhaler (ACC) \\
\hline 1 & Unscrew and remove the cap from the inhaler & Open lever \\
\hline 2 & Keep inhaler upright & Push lever back completely to load dose \\
\hline 3 & Rotate grip one way, then back, to load dose & Exhale all air out of lungs \\
\hline 4 & Exhale all air out of lungs & Exhale away from the mouthpiece ${ }^{a}$ \\
\hline 5 & Exhale away from the mouthpiece $^{a}$ & Hold Inhaler horizontally \\
\hline 6 & Keep head upright, lift chin slightly & Place mouthpiece between teeth and seal with lips \\
\hline 7 & Place mouthpiece between teeth and seal with lips & Inhale slowly and deeply ${ }^{a}$ \\
\hline 8 & Inhale forcefully and deeply ${ }^{a}$ & Hold breath for as long as is comfortable (aim for $10 \mathrm{~s}$ ) \\
\hline 9 & Pause, then breathe out normally ${ }^{a}$ & Exhale away from the inhaler ${ }^{a}$ \\
\hline 10 & Exhale away from the inhaler & Close inhaler \\
\hline 11 & Replace cap & \\
\hline
\end{tabular}

Based on checklists developed in collaboration with the National Prescribing Service (Sydney, Australia) and manufacturer approved.

${ }^{\text {a}}$ Steps for which the Inhalation Manager provided additional visual feedback.

patients with the correct technique (Pearson's Chi-Square test) were compared between groups. Group comparisons were based on measurements at V1 and V2.

Data were analysed using the IBM Statistical Package for Social Science (SPSS, version 19, IBM, Armonk, NY, USA). A significance level of 0.05 was used.

\section{RESULTS}

Of the 101 recruited participants, 97 participants completed the study.

Demographic data of participants are displayed in Table 2. There were no statistically significant differences between groups with regard to demographic factors $(P>0.05, n=101$, Pearson's Chi-Square test).

\section{Baseline}

Asthma control. There was no statistically significant difference between Group 1 and Group 2 with regard to mean asthma control score at V1 (Table 2) (1.6 (s.d. 1.0) and 1.7 (s.d. 1.0) respectively $n=101, P=0.4$, Mann-Whitney $U$ Test).

Technique. Initially, $4 \%$ of Group 1 and $6 \%$ of Group 2 demonstrated correct technique (mean inhaler technique scores
6.8 (s.d. 1) and 6.8 (s.d. 1), respectively (mean (s.d.)). There was no statistically significant difference between Group 1 and Group 2 at V1 (proportions: $n=101, P=0.982$, Pearson's Chi-Square test; means: $n=101, P=0.975$, Mann-Whitney $U$ Test).

For the ACC, the most common errors were associated with step 3 (Exhale to residual volume), step 4 (Exhale away from the mouth piece) and step 8 (Hold breath for $5 \mathrm{~s}$ ).

For the $\mathrm{TH}$, the most common errors were associated with step 2 (Keep inhaler upright during loading), step 4 (Exhale to residual volume) and step 5 (Exhale away from the mouth piece).

At the completion of V1 (training session), all participants in Groups 1 and 2 were able to demonstrate correct technique.

Follow-up

Effect of education. Compared with V1, at V2 there was a statistically significant increase in the proportion of participants with correct inhaler technique: from $4 \%$ to $51 \%$ among Group 1 participants and from $6 \%$ to $83 \%$ among Group 2 participants (Pearson's Chi-Squared, $P=0.03, n=49$ and Pearson's Chi-Squared, $P=0.01, n=48$, respectively).

The magnitude of increase in the proportion of participants with correct inhaler technique was statistically significantly higher 
Table 2. Participant characteristics

\begin{tabular}{|c|c|c|c|}
\hline & $\begin{array}{l}\text { All participants } \\
\quad(\mathrm{n}=101)\end{array}$ & $\begin{array}{l}\text { Group } 1 \\
(\mathrm{n}=50)\end{array}$ & $\begin{array}{l}\text { Group } 2 \\
(\mathrm{n}=51)\end{array}$ \\
\hline Female, $n(\%)$ & $66(65.3 \%)$ & 35 (70\%) & 31 (60.8\%) \\
\hline Accuhaler users, $n(\%)$ & $54(53.5 \%)$ & $26(52 \%)$ & $28(54.9 \%)$ \\
\hline \multicolumn{4}{|l|}{ Age } \\
\hline $18-25$ years & $24(23.8 \%)$ & $11(22.0 \%)$ & $13(25.5 \%)$ \\
\hline $26-40$ years & $21(20.8 \%)$ & $11(22.0 \%)$ & 10 (19.6\%) \\
\hline $41-60$ years & $25(24.8 \%)$ & $10(20.0 \%)$ & 15 (29.4\%) \\
\hline $61+$ years & $31(30.7 \%)$ & $18(36.0 \%)$ & $13(25.5 \%)$ \\
\hline $\begin{array}{l}\text { Previous information } \\
\text { received on how to } \\
\text { use the inhaler, } n(\%)\end{array}$ & $89(88.0 \%)$ & $41(82.0 \%)$ & $48(94.0 \%)$ \\
\hline \multicolumn{4}{|c|}{ Source of previous inhaler information, $\mathrm{n}(\%)$} \\
\hline General practitioner & 48 (54.5\%) & $24(58.5 \%)$ & $24(50.0 \%)$ \\
\hline Pharmacist & 15 (16.9\%) & $6(14.6 \%)$ & $9(18.8 \%)$ \\
\hline $\begin{array}{l}\text { A doctor+a } \\
\text { pharmacist }\end{array}$ & $23(25.8 \%)$ & $10(24.3 \%)$ & $13(27.1 \%)$ \\
\hline CMI & $2(2.2 \%)$ & $1(2.4 \%)$ & $1(2.1 \%)$ \\
\hline Pulmonary nurse & $1(1.1 \%)$ & $0(0 \%)$ & $1(2.1 \%)$ \\
\hline \multicolumn{4}{|c|}{ Form of information previously received, $\mathrm{n}(\%)$} \\
\hline $\mathrm{PD}+\mathrm{VI}$ & $35(39.3 \%)$ & $18(43.9 \%)$ & $17(35.4 \%)$ \\
\hline VI only & 19 (21.3\%) & $10(24.4 \%)$ & 9 (18.75\%) \\
\hline WI only & $13(14.6 \%)$ & 5 (12.2\%) & $8(16.7 \%)$ \\
\hline $\mathrm{WI}+\mathrm{VI}$ & $1(1.1 \%)$ & $1(2.4 \%)$ & $0(0 \%)$ \\
\hline $\mathrm{Wl}+\mathrm{PD}+\mathrm{VI}$ & $21(23.6 \%)$ & $7(17.1 \%)$ & $14(29.2 \%)$ \\
\hline \multicolumn{4}{|c|}{ Time length since last duration, $\mathrm{n}(\%)$} \\
\hline$<1$ month & $2(2.2 \%)$ & $2(4.9 \%)$ & $0(0 \%)$ \\
\hline $1-5$ months & $19(21.3 \%)$ & $8(19.5 \%)$ & $11(22.9 \%)$ \\
\hline 6-11 months & $7(7.9 \%)$ & $2(4.9 \%)$ & $5(10.4 \%)$ \\
\hline $1-2$ years & $26(29.2 \%)$ & 13 (31.7\%) & 13 (27.1\%) \\
\hline$>2$ years & $35(39.3 \%)$ & $16(39.0 \%)$ & $19(39.6 \%)$ \\
\hline $\begin{array}{l}\text { Asthma Control } \\
\text { Questionnaire score at } \\
\text { baseline (mean } \pm \text { s.d.) }\end{array}$ & $1.67 \pm 0.98$ & $1.70 \pm 1.01$ & $1.60 \pm 0.96$ \\
\hline \multicolumn{4}{|c|}{$\begin{array}{l}\text { Abbreviations: CMI, consumer medicine information; IM, Inhalation } \\
\text { Manager; PD, physical demonstration; VI, verbal information; WI, writter } \\
\text { information. } n=49 \text { in Group } 1 \text { (ACC, } n=27 ; \mathrm{TH}, n=22), n=48 \text { in Group } \\
\text { (ACC, } n=26 ; \mathrm{TH}, n=22 \text { ). }\end{array}$} \\
\hline
\end{tabular}

for Group 2 compared with Group 1 ( $n=97, P=0.02$, Pearson's Chi-Square test) (Figure 3).

At V2, there was a statistically significant improvement in the mean inhaler technique score from 6.8 (s.d. 1) to 8.9 (s.d. 1) (mean (s.d.)) for Group 1 (Wilcoxon's Signed Rank test, $P=0.04, n=49$ ) and from 6.8 (s.d. 1) to 9.5 (s.d. 1) (mean (s.d.)) for Group 2 (Wilcoxon's Signed Rank test, $P=0.02, n=48$ ). The magnitude of improvement in Group 2 was statistically significantly greater than that in Group 1 (Mann-Whitney $U$ test, $P=0.002, n=97$ ).

For the $\mathrm{ACC}$ and $\mathrm{TH}$, the most common errors remained the same, but the proportion of patient participants performing them incorrectly decreased.

At V2, there was no statistically significant difference in mean Asthma Control score for Groups 1 and 2 (1.4 (s.d. 0.8) and 1.3 (s.d. 1.0) respectively, Mann-Whitney $U$ Test, $P=0.5, n=97)$.

There was a statistically significant improvement in the Asthma Control Score in Group 1 when comparing the score at V1 with the score at V2 (1.6 (s.d. 1.0) and 1.4 (s.d. 0.8), respectively, Wilcoxon-Signed Rank test, $P=0.004, n=49$ ).

There was a statistically significant improvement in the Asthma Control Score in Group 2 when comparing score at V1 with the

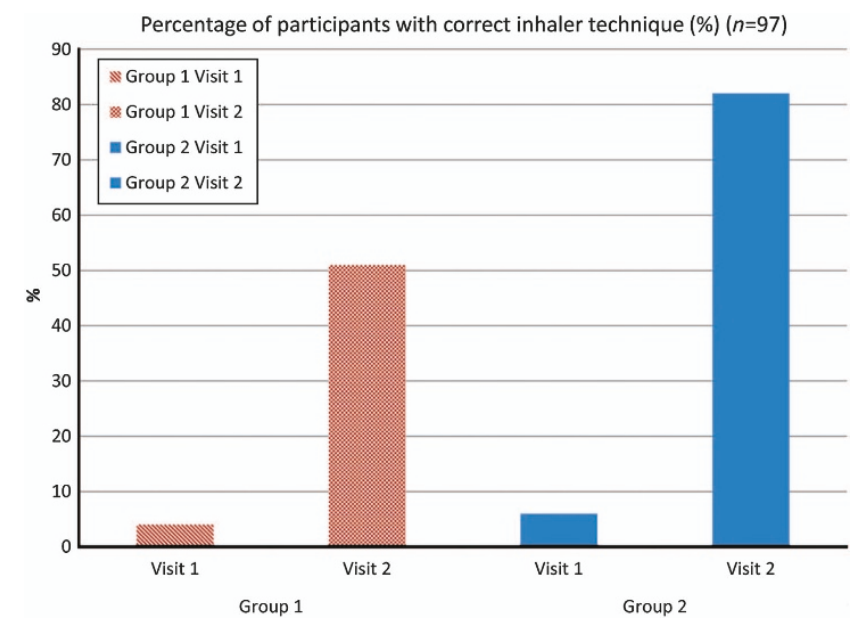

Figure 3. Proportion of participants with correct inhaler technique at Visit 1 and Visit 2.

score at V2 (1.7 (s.d. 1.0) and 1.3 (s.d. 1.0), respectively, Wilcoxon's Signed Rank test, $P=0.03, n=48$ ).

\section{DISCUSSION}

Main findings

This study compared the effectiveness of two community pharmacy-delivered educational interventions, one based on qualitative visual feedback ${ }^{15}$ and another with additional quantitative visual feedback, on the maintenance of correct inhaler technique over time. These results show that qualitative and quantitative feedback is more effective than qualitative feedback alone. With this dual-format feedback, $83 \%$ of participants are able to maintain the correct technique after 1 month. This is significantly higher than that achieved by other research or interventions. $^{2-9}$

This study is unique as for the first time it explored the relationship between 'feedback' and inhaler technique. To date, only qualitative feedback has been used in this field of research despite evidence indicating that, when teaching a skill, quantitative feedback is preferred. ${ }^{19}$ Therefore, it is not surprising that the quantitative feedback evaluated in this research was more effective in maintaining the skill of correct inhaler technique over time when compared with the more traditional qualitative feedback. Quantitative feedback (through the graphical representation of inhaler technique, which is compared with optimal technique by the IM) provides a tangible quantitative goal for the patient, allowing them to conceptualise exactly what errors they need to correct (e.g., if they are not breathing in 'forcefully and deeply' how much is enough?). Objective (graphical) feedback (as tested in this research) is a form of visual feedback that may be a way to help 'quantify' the information provided. ${ }^{27,28}$ Further, an important component of learning a skill and improving performance is the ability to detect and correct errors. ${ }^{29}$ The quantitative feedback used in this research is therefore also helpful in goal setting, which the patient can quantify to a tangible and attainable extent. The feedback from the IM allows a pharmacist to articulate this goal more clearly. The steps associated with breathing manoeuvres are also quite subjective to 'reflect on', and therefore there is an opportunity for miscommunication with regard to what extent the breathing manoeuvres described should be carried out. In other words, unless patients can objectively identify a goal, they may only subjectively evaluate their technique. This is primarily because, up until now, HCPs have had no quantitative means of providing feedback with regard to inhaler technique. 
Interpretations of findings in relation to previously published work The new method of education explored in this study incorporated the theoretical framework associated with the concept of 'feedback' and, in so doing, proved to be more effective than the current evidence-based inhaler technique education delivered through the community pharmacy. One month after the interventions were delivered, $51 \%$ of patient participants in the standard intervention group (Group 1) continued to have an incorrect inhaler technique. This is consistent with previously published studies that have found that approximately $50 \%$ of patients who receive education via a physical demonstration by the HCP using a placebo inhaler continue to have an incorrect technique 1 month after their training session. ${ }^{7}$ In this research, the participants who received verbal feedback, physical demonstration and the quantitative visual feedback were significantly more likely to maintain the correct inhaler technique, with $83 \%$ of participants being able to maintain the correct technique. This is a vast improvement in the maintenance of correct technique from that previously demonstrated in other research. ${ }^{2-9}$

When it comes to the actual steps performed incorrectly, for the $\mathrm{TH}$, holding the device upright, exhaling to residual volume prior to inhalation and exhaling away from the inhaler were the most problematic steps; for the ACC, exhaling to residual volume, exhaling away from the inhaler and holding breath for $5 \mathrm{~s}$ were most commonly performed incorrectly. These results are consistent with the findings of many previous studies. ${ }^{5,6,15,30-32}$ With regard to the quantitative feedback provided by the $I M$, it is important to note that the specific steps for which the quantitative feedback is provided are not necessarily those for which the IM provides feedback. Despite this, the quantitative feedback was more effective than the qualitative feedback (verbal plus physical demonstration) alone. There may be several explanations for this. One of them may relate to participant confidence; i.e., by providing the participants with visual quantitative feedback, they may have been reassured about their ability to use the inhalers. It is also possible that once they were reassured of the steps they performed correctly (e.g., breathing in forcefully and deeply) they were more likely to concentrate on the problematic incorrect steps that they had been shown. The use of quantitative feedback may also have had a role in motivating patients to use their device correctly. Ovchinikova et $a l^{16}$ found that patient motivation was a determining factor in device technique maintenance.

Implications for future research, policy and practice

This research highlights the importance of feedback in educating patients in the correct use of their Dry Powder Inhalers. Future research should aim to explore this novel educational intervention in the maintenance of inhaler technique in those patients using other devices - e.g., the pressurised metered dose inhaler. Both groups showed significant improvement in asthma control at the 1-month follow-up. Although a link between inhaler technique and asthma control has previously been shown, ${ }^{8}$ asthma control can be attributed to factors other than inhaler technique. These may be related to adherence, trigger avoidance, improved selfmanagement, smoking cessation, etc, during the study. Thus, further exploration of the nature of the relationship between inhaler technique and asthma control is needed.

\section{Strengths and limitations of this study}

The major strength of this study lies in the fact that this study explored a new approach to feedback and has shown that this makes a difference in inhaler technique maintenance. The main limitation lies in the impact of the IM on the pharmacist's ability to evaluate the technique. Potentially, pharmacists utilising the IM to deliver education may have had more interaction both with the researcher and with the patient participant. This may have positively influenced their ability to evaluate the technique.

\section{Conclusions}

This study shows that an educational intervention for inhaler technique, which is based on both qualitative and quantitative feedback, is more effective than one based on qualitative feedback alone in maintaining the correct inhaler technique over time. Further studies are needed to explore whether this effect is maintained beyond the study follow-up period and the nature of the relationship between asthma control and inhaler technique.

\section{ACKNOWLEDGEMENTS}

The authors thank Christine Wasef for her assistance with data collection and Teva Pharmaceuticals Ltd for providing the Inhalation Managers used in the study.

\section{CONTRIBUTIONS}

Mariam Toumas-Shehata: the guarantor, study design, training of pharmacists, data collection and analyses, and writing up the manuscript. David Price: study design, review of data analyses, writing up and editing the manuscript. Iman Basheti: review of study design, data analyses and editing the manuscript. Sinthia Bosnic-Anticevich: study design, training of pharmacists, data analyses, writing up and editing the manuscript.

\section{COMPETING INTERESTS}

David Price has consultancy arrangements with Boehringerlngelheim, GlaxoSmithKline, Merck, Mundipharma, Novartis, Chiesi and Teva. He or his research team have received grants and support for research in respiratory disease from the following organisations in the past 5 years: UK National Health Service, Aerocrine, AstraZeneca, Boehringer Ingelheim, Cipla, GlaxoSmithKline, Merck, Mundipharma, Novartis, Nycomed, Pfizer, Chiesi and Teva. He has spoken for: AstraZeneca, Boehringer Ingelheim, Chiesi, Cipla, GlaxoSmithKline, Merck, Mundipharma, Pfizer and Teva. He has shares in AKL Ltd which produces phytopharmaceuticals. He is the sole owner of Research in Real Life Ltd. Sinthia Bosnic-Anticevich has no shares in any pharmaceutical companies. In the past 5 years, she has provided consulting on the topic of inhaler device use to Pharmaceutical Society of Australia and the Pharmacy Guild of Australia. She has received research funding from the Australian Commonwealth Government Department of Health and the Australian Research Council. She has consultancy agreements and honoraria for presentation with Mundipharma and Teva. The remaining authors declare no conflict of interest.

\section{FUNDING}

This study was funded by the Australian Postgraduate Award.

\section{REFERENCES}

1 NACA. Asthma Management Handbook. 6th edn. National Asthma Council Australia: Australia, 2006.

2 Shrestha M, Parupia H, Andrews B, Kim SW, Martin MS, Park DI et al. Metered-dose inhaler technique of patients in an urban ED: prevalence of incorrect technique and attempt at education. Am J Emerg Med 1996; 14: 380-384.

3 Fink JB, Rubin BK. Problems with inhaler use: a call for improved clinician and patient education. Respir Care 2005; 50: 1360-1374.

4 Crompton GK. The adult patient's difficulties with inhalers. Lung 1990; 168(Suppl): 658-662.

5 Epstein S, Maidenberg A, Hallett D, Khan K, Chapman KR. Patient handling of a dry-powder inhaler in clinical practice. Chest 2001; 120: 1480-1484.

6 Molimard M, Raherison C, Lignot S, Depont F, Abouelfath A, Moore N. Assessment of handling of inhaler devices in real life: an observational study in 3811 patients in primary care. J Aerosol Med 2003; 16: 249-254.

7 Basheti IA, Reddel HK, Armour CL, Bosnic-Anticevich SZ. Counseling about turbuhaler technique: needs assessment and effective strategies for community pharmacists. Respir Care 2005; 50: 617-623. 
8 Basheti IA, Reddel HK, Armour CL, Bosnic-Anticevich SZ. Improved asthma outcomes with a simple inhaler technique intervention by community pharmacists. J Allergy Clin Immunol 2007; 119: 1537-1538.

9 Lavorini F, Magnan A, Dubus JC, Voshaar T, Corbetta L, Broeders M et al. Effect of incorrect use of dry powder inhalers on management of patients with asthma and COPD. Respir Med 2008; 102: 593-604.

10 Bosnic-Anticevich SZ, Sinha H, So S, Reddel HK. Metered-dose inhaler technique: the effect of two educational interventions delivered in community pharmacy over time. J Asthma 2010; 47: 251-256.

11 Giraud V, Allaert FA. Improved asthma control with breath-actuated pressurized metered dose inhaler (pMDI): the SYSTER survey. Eur Rev Med Pharmacol Sci 2009; 13: $323-330$.

12 Giraud V, Allaert F, Roche N. Inhaler technique and asthma: feasibility and acceptability of trianing by pharmacists. Respir Med 2011; 105: 1815-1822.

13 McElnay JC, Scott MG, Armstrong AP, Stanford CF. Audiovisual demonstration for patient counselling in the use of pressurised aerosol bronchodilator inhalers. J Clin Pharm Ther 1989; 14: 135-144.

14 Skaer TL, Wilson CB, Sclar DA, Arnold TA, Garcia CF, Schmidt LN et al. Metereddose inhaler technique and quality of life with airways disease: assessing the value of the Vitalograph in educational intervention. J Int Med Res 1996; 24 369-375.

15 Basheti IA, Armour CL, Bosnic-Anticevich SZ, Reddel HK. Evaluation of a nove educational strategy, including inhaler-based reminder labels, to improve asthma inhaler technique. Patient Educ Couns 2008; 72: 26-33.

16 Ovchinikova L, Smith L, Bosnic-Anticevich S. Inhaler technique maintenance: gaining an understanding from the patient's perspective. J Asthma 2011; 48 616-624.

17 Nimmo CJ, Chen DN, Martinusen SM, Ustad TL, Ostrow DN. Assessment of patient acceptance and inhalation technique of a pressurized aerosol inhaler and two breath-actuated devices. Ann Pharmacother 1993; 27: 922-927.

18 van der Palen J, Klein JJ, Kerkhoff AH, van Herwaarden CL, Seydel ER. Evaluation of the long-term effectiveness of three instruction modes for inhaling medicines. Patient Educ Couns 1997; 32(1 Suppl): S87-S95.

19 Kovacs G. Procedural skills in medicine: linking theory to practice. J Emerg Med 1997; 15: 387-391.

20 Bosnic-Anticevich S., Stuart M, Mackson J, Cvetkovski B, Sainsbury E, Armour C et al. Development and evaluation of an innovative model of interprofessional education focused on asthma medication use. BMC Med Educ 2014; 14: 72.

21 Juniper EF, Svensson K, Mörk AC, Ståhl E. Measurement properties and interpretation of three shortened versions of the asthma control questionnaire. Respir Med 2005; 99: 553-558.
22 Juniper EF, Bousquet J, Abetz L, Bateman ED. GOAL Committee. Identifying 'well-controlled' and 'not well-controlled' asthma using the Asthma Control Questionnaire. Respir Med 2006; 100: 616-621.

23 Lavorini F, Levy ML, Corrigan C, Crompton G. ADMIT Working Group. The ADMIT series - issues in inhalation therapy. 6) Training tools for inhalation devices. Prim Care Respir J 2010; 19: 335-341.

24 Armour C, Bosnic-Anticevich S, Brillant M, Burton D, Emmerton L, Krass I et al. Pharmacy Asthma Care Program (PACP) improves outcomes for patients in the community. Thorax 2007; 62: 496-502.

25 Basheti IA, Armour CL, Bosnic-Anticevich SZ, Reddel HK. Evaluation of a novel educational strategy, including inhaler-based reminder labels, to improve asthma inhaler technique. Patient Educ Couns 2008; 72: 26-33.

26 Bosnic-Anticevich SZ, Sinha H, So S, Reddel HK. Metered-dose inhaler tehcnique: the effect fo two educational interventions delivered in community pharmacy over time. J Asthma 2010; 47: 251-256.

27 Triano JJ, Scaringe J, Bougie J, Rogers C. Effects of visual feedback on manipulation performance and patient ratings. J Manipulative Physiol Ther 2006; 29: 378-385.

28 Casey AM, McWilliam RA. Graphical feedback to increase teacher's use of incidental teaching. J Early Interv 2008; 30: 251-268.

29 Schmidt RA.. The Schema as a Solution to Some Persistent Problems in Motor Learning Theory. Academic Press: New York, NY, USA, 1976.

30 van der Palen J, Klein JJ, Kerkhoff $\mathrm{AH}$, van Herwaarden $\mathrm{CL}$. Evaluation of the effectiveness of four different inhalers in patients with chronic obstructive pulmonary disease. Thorax 1995; 50: 1183-1187.

31 Ronmark E, Jögi R, Lindqvist A, Haugen T, Meren M, Loit HM et al. Correct use of three powder inhalers: comparison between Diskus, Turbuhaler, and Easyhaler. J Asthma 2005; 42: 173-178.

32 Melani AS, Zanchetta D, Barbato N, Sestini P, Cinti C, Canessa PA et al. Inhalation technique and variables associated with misuse of conventional metered-dose inhalers and newer dry powder inhalers in experienced adults. Ann Allergy Asthma Immunol 2004; 93: 439-446.

This work is licensed under a Creative Commons Attributioncc) NonCommercial-NoDerivatives 4.0 International License. The images or other third party material in this article are included in the article's Creative Commons license, unless indicated otherwise in the credit line; if the material is not included under the Creative Commons license, users will need to obtain permission from the license holder to reproduce the material. To view a copy of this license, visit http:// creativecommons.org/licenses/by-nc-nd/4.0/ 